\title{
Environmental Concept of Indigo Materials in Chinese White Trousers Yao National Costume
}

ISSN: 2576-8840

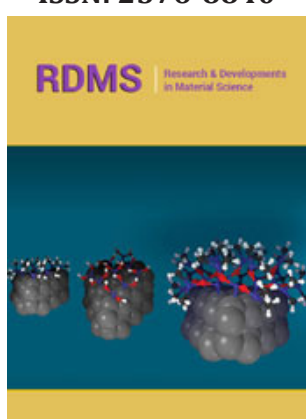

*Corresponding author: Longwei Luan, Hanshan Normal University, Chaozhou 521041, Guangdong, China

Submission: 酽 October 05, 2020

Published: 非 October 16, 2020

Volume 14 - Issue 2

How to cite this article: Longwei Luan, Ning Han. Environmental Concept of Indigo Materials in Chinese White Trousers Yao National Costume. Res Dev Material Sci. 14(2). RDMS.000834. 2020. DOI: 10.31031/RDMS.2020.14.000834

Copyright@ Longwei Luan. This article is distributed under the terms of the Creative Commons Attribution 4.0 International License, which permits unrestricted use and redistribution provided that the original author and source are credited.

\author{
Longwei Luan ${ }^{1,2 *}$ and Ning Han $^{3}$ \\ ${ }^{1}$ Hanshan Normal University, Guangdong, China \\ ${ }^{2}$ Cheongju University, Chungbuk, Korea \\ ${ }^{3}$ Xingzhixuan Technology Co., LTD, China
}

\begin{abstract}
"Indigo dyeing" is an ancient traditional Dyeing process in China, which has the reputation of "the first dyeing in the East". The indigo dye is an essential technology in white trousers clothing. The material follows the ecological cycle of "from the people and from the people". The material indigo is also made from indigo plants, which is degradable and can reduce environmental pollution to the maximum extent.

Keywords: Anti-dyeing; Dyeing; Indigo dye
\end{abstract}

\section{Opinion}

\section{Selection and application of indigo dye material for white trousers}

In the world of manual printing and dyeing, articles of daily use or works of art made by preventive dyeing have a long history and are widely used. The principle of anti-dyeing process is a work of unique artistic style presented in the opposite state of "anti-dyeing" and "dyeing". The preparation of indigo dye for white trousers is mainly divided into the preparation of anti-dye material and the preparation of dyeing cloth material.

\section{Preparation of anti-dyeing materials}

Yao costume of white trousers is a kind of costume combined with painting and embroidery. Both women's jacket and pleated skirt need to use self-made wax dyeing tool to draw "painting" with their own national characteristics before dyeing, which is known locally as "sticky paste painting". The "sticky paste" used in the "sticky paste" painting is the main anti-dyeing material, which is also the biggest difference between white pants Yao and other nationalities who use beeswax, paraffin and other materials to prevent dyeing. The paste is produced from the SAP of a native toona plant and is collected in a manner similar to that of rubber. Generally, a tree can flow 8 to 10 kilograms of sticky paste, more when the sun shines. Paint a picture with sticky paste alone is not enough, you also need another anti-dye material, that is butter. Mix the paste and butter 1:1 into a small black iron pot, burn the corn stalk and heat it for 3-4 hours to make it fully blend into a dark brown color, set aside. At this time, anti-dye materials for making the paste painting are ready. In the production and living area of white trousers, sticky paste trees are commonly planted, and the materials are easy to be obtained and used. Using adhesive paste to prevent dyeing, the effect is more obvious than beeswax, the pattern is more beautiful after dyeing. In the anti-stain material, the paste is mixed with butter, which has a low melting point and can reduce the burn injury. Short heating time, will not produce toxic smoke, residue green environmental protection.

\section{Preparation of dyeing materials}

White pants yao indigo dyeing process follows the "ecological cycle, by the people", the main indigo dyeing material is taken from the indigo plant, the indigo natural fermentation, match into the quicklime, rapid agitation, make its rapid convergence, and placed a week or so, there will be precipitation at the bottom of the bucket, this is the main material of dyed indigo. When used, it is reconfigured with self-made grain wine and grass ash, which gives out primitive and natural colors with natural ecological aesthetic feeling. 


\section{Environmental protection concept of indigo dye for white trousers}

The traditional batik prevention is to mix paraffin wax and beeswax and boil them, which will produce harmful smoke, harm human health, pollute the environment.

Perchloroethylene is a toxic chemical that needs to be used for washing, and many countries have banned the use of this dry detergent. Both indigo dyeing and anti-dyeing materials are materials made from the people, which reflects the concept of environmental protection in the ecological cycle. In addition, the indigo dye in white pants adopts the method of artificial fermentation and reduction dyeing. The principle of this method is that indigo is not easy to be dyed, and microorganisms such as yeast need to be added. After the microorganisms secrete biological enzymes, indigo can be gradually reduced to indigo that is suitable for dyeing. Therefore, when the Baikuyao people are dyed, adding quicklime and sorghum wine into the blended fuel is to use this principle to restore the indigo that was not suitable for dyeing to indigo white. No chemical materials were added in the whole process. Compared with all kinds of modern dyeing materials, although indigo dye for white trousers is not complete in color chromatography and has no high color fastness as modern dyeing materials, there is no environmental pollution in the whole process of production and use, and all materials can be degraded. If you want a dark blue or black cloth, you also need a colorant, and the local choice of colorant is a local root plant. After dyeing the cloth, the spinning and dyeing materials are the leaves of caulis SPP. In addition, as the raw material of indigo is originally a medicinal plant, indigo has a certain health care effect in the process of using clothes. These environmental protection ideas are the embodiment of modern chemical materials cannot achieve.

Cotton is spun into thread and woven into cloth, and natural plants are used to make dye-proofing agent and dye. From production to production, it contains a natural beauty of handwork, and expresses the respect of white pants yao people to nature. Yao Indigo dye in white trousers is a natural ecological thing and phenomenon passed down from generation to generation. From the perspective of aesthetic value and environmental protection concept of material application, it is worth passing down this ancient national craft.

\section{Acknowledgement}

This work was supported by Guangdong Province Office of Education (2019GXJK083) and Hanshan Normal University (XS202022). 